\begin{tabular}{l} 
RCCS \\
\hline Annual Review
\end{tabular}

\section{RCCS Annual Review}

A selection from the Portuguese journal Revista Crítica de Ciências Sociais

7| 2015

Issue no. 7

\title{
The Representation of the Illegal Migrant in Contemporary Cinema: Border Scenarios and Effects
}

\section{Fabrice Schurmans}

Translator. João Paulo Moreira

\section{OpenEdition}

\section{Journals}

Electronic version

URL: http://journals.openedition.org/rccsar/622

DOI: $10.4000 /$ rccsar.622

ISSN: $1647-3175$

\section{Publisher}

Centro de Estudos Sociais da Universidade de Coimbra

\section{Electronic reference}

Fabrice Schurmans, «The Representation of the Illegal Migrant in Contemporary Cinema: Border Scenarios and Effects », RCCS Annual Review [Online], 7 | 2015, Online since 01 October 2015, connection on 19 April 2019. URL : http://journals.openedition.org/rccsar/622 ; DOI : 10.4000/ rccsar.622 


\section{Fabrice Schurmans}

Centre for Social Studies, University of Coimbra, Portugal

\section{The Representation of the Illegal Migrant in Contemporary Cinema: Border Scenarios and Effects"}

This paper analyzes a corpus of films that represent various journeys of illegal migrants. It focuses specifically on the role of the illegal migrant on the border, understood as both a place and a metaphor. After critically examining the notion of border, it explores the recurring characters in this particular kind of film: the illegal migrant who experiences the border, the Western man-in-crisis who is regenerated through contact with the Other, the immigration officer whose own stance toward the suffering of illegal migrants is questioned.

Keywords: border relations; border representation; cinema; illegal migrant.

A number of contemporary films have used the figure of the illegal migrant in Western societies to the point of almost starting a new subgenre (Sotinel, 2009; Mandelbaum and Sotinel, 2011; Mandelbaum and Ridet, 2011). Whatever his or her place of origin, the migrant in these films is defined as a border being, subject to a variety of border effects. As we shall see, there is more to these borders than the mere dividing lines between countries or the European Union's external frontiers. The border in these films is not synonymous with a specific geographical context signaled by posts or by boundary markers, but is rather presented as a demarcation between the legally acknowledged citizen and the officially nonexistent subject. The aim of the present paper is precisely to address the nature of the representation of the border in a number of contemporary films. ${ }^{1}$

The whole issue of representation makes it imperative to ponder the nature of the analysis to be used. Although a fiction film - just like any novel, for that matter - comes out of a given society and is determined, at least in part, by that society, it would be wrong to see it as a simple reflection of social circumstances and therefore approach it as if it were a mere document. It is not a question of studying the aesthetic configurations and then proceed to see how they convey reality, but rather of understanding how a particular

\footnotetext{
* Article published in Portuguese in RCCS 105 (December 2014). DOI: 10.4000/rccs.5814

${ }^{1}$ The corpus under discussion includes Fast Food Nation (Linklater, 2006), Gran Torino (Eastwood, 2008), Lilya 4-Ever (Moodysson, 2002), Promised Land (Gitai, 2004), Le Silence de Lorna (Dardenne, 2008), Trance (Villaverde, 2006), The Visitor (McCarthy, 2007) and Welcome (Lioret, 2009). I chose not to include Taken (Morel, 2008) because it turns the illegal migrant into a paradigm of absolute evil. In Morel's film there is no border per se, because the migrant and the Western man-in-crisis (in this case, a crisis caused by his daughter's having been abducted by Albanian migrants) never truly share the space for an encounter where an alternative sociability might flourish.
} 
aesthetic configuration is linked to a crucial social problem. For example, what does a given shot scale or the choice of a certain type of camera tell us about the implied social context?

Two other aspects should be stressed: the virtually exclusive focus on the illegal migrant, and the choice of a fictional, as opposed to a documentary, approach. In fact, the illegal migrant is far from being representative of migration as a whole. According to the UN Development Program's Human Development Report on Migrations (UNDP, 2009), this is a complex phenomenon, not only heterogeneous but also very diverse in nature. As a consequence, one is faced with the difficult task of lumping together a wide variety of experiences under the sole concept of migration. The report in question addresses illegal migration as one category among several others, including economic and conflict-induced migration. But as the report shows on more than one occasion, this also happens to be the most difficult type of migration for one to study (the very fact that it is an illegal activity accounts for the lack of reliable data as well as for the difficulty of gaining access to victims and the difficulty of telling what is voluntary from what is forced behavior) (UNDP, 2009: 23, 73-75). ${ }^{2}$ These traits are precisely the reason why the screenwriters of films about illegal migrants opted for fiction instead of the documentary mode, as the former is better equipped to fill the gaps and silences, to convey the suffering of characters and thus to move, which in this particular context is much the same as involving the viewer.

But the very word fiction poses another problem, since this kind of work is also characterized by a diversity of aesthetic approaches, from the cinema of illusion, with its classic narrative structure (e.g. Welcome, The Visitor), to the cinema of allusion and narrative boldness (e.g. Le Silence de Lorna, Promised Land, Trance) - which helps explain, at least in part, why the latter variety tends to be less popular with the public. Perhaps the films in the former group also owe their success to the incorporation of the figure of a Western citizen going through a personal crisis and whose life is disrupted when intruded upon by the illegal migrant. More on the main features of this stock character later.

\footnotetext{
${ }^{2}$ There is an overall lack of clear data on migratory movements, which is why the UNDP states that many aspects of migration fail to be covered by national governments in the North when they formulate their migration policies (UNDP, 2009: 31). Perhaps this is the reason why, in Sarkozy's France, the fight against illegal immigration and the turning of a social phenomenon into a political problem were carried out in the name of values rather than real facts (when the latter, in point of fact, suggest the total absence of the alleged invasion) (Fassin, 2009: 22). In this context, the representations of the illegal migrant in a variety of public discourses (in politics, the media, etc.) are largely the cause of a pervasive fear in society at large, which in turn only reinforces those representations (Nasraoui, 2013: 93, 129).
} 


\section{The Illegal Migrant in Fiction: A Border Subject}

First an attempt will be made to define what has proved to be a heuristically exciting concept in the area of the humanities and social sciences. Next we will see that the background of some of these migrant figures becomes significant, first and foremost, in light of their experiences on the border. Our goal, of course, is not to offer an in-depth, detailed study of the complexity of the entire border phenomenon, but to foreground some of its features, to shed light on the path that led from literal to metaphorical use, and to figure out to what extent the concept in question may prove useful to film analysis.

Of late, the human and social sciences have shown a keen interest in the border, or rather in the border phenomenon (a phrase that manages to capture the dynamic, plural dimension of relationships on the border) in a global perspective. With the deterritorialization of whole sections of socio-economic activities, as well as the delegation of power and sovereignty from the national to the European level, both the concept and the reality of the border have evolved. To be more precise, the border has shifted from boundary markers and checkpoints to fenced-in camps and other transit zones for illegal migrants, i.e. it has been reconfigured, while the free movement of certain individuals has been increasingly hindered (Makaremi, 2008; Sassen, 2002).

First of all, even when borders purport and claim to be watertight ( $\mathrm{l}$ am thinking here of the various walls under construction, from the one between the United States and Mexico to the one currently being built by Israel in the West Bank), they are still a site of transit and contact, where, paradoxically, the possibility persists of a bridge between subjects, socioeconomic practices, etc. This idea is expressed by the editors in the opening pages of a special issue of Cultures \& Conflits devoted to the question of borders:

It is certainly nothing new to affirm that borders make the world and that along those national borders a certain kind of place tends to take shape that is very paradoxical in nature, in that it seems to deny the very possibility of the border by generating bridges and continuities where, most often than not, the body politic would rather welcome (socially sterile) rupture and restrictions to the exercise of sovereignty. (Bennafla and Peraldi, 2008) ${ }^{3}$

\footnotetext{
${ }^{3}$ This is clearly the case of the border between India and Bangladesh. The Indian Government has constructed a social discourse about the border extolling its inviolability and the country's full control over it, a claim easily disproved by all the evidence on the ground: "The border is permeable and accommodating. And that is the ultimate proof that necessity makes law and that the facts on the ground laugh in the face of nationalist politics and the false identities it contrives" (Rush, 2012: 6). But this gap between political discourse and social practices is the exact reason why, instead of favoring emancipation (except for the economic emancipation of just a few), the border harbors exploitation, smuggling and violence.
} 
The majority of the anthropological and sociological studies in the abovementioned issue corroborate the global nature of the border phenomenon and the transformation of the role played by the border, especially in the North. In fact, regardless of geographical context, today's border is at odds with the official discourses about it (control, impermeability, permanent surveillance). In other words, instead of a simple, easy to grasp border situation, we have multiple situations whose complexity makes borders not just elusive but also theoretically challenging (Bennafla and Peraldi, 2008).

On the other hand, the North has witnessed a radical transformation in the role of the border, which went from being a mark/affirmation of military-related national sovereignty (as conveyed in the etymology of the word "frontier") to being a policing-related site for controlling, containing and rejecting illegal immigrants. The process of European unification and its corollary in terms of abolishing the EU's internal borders, or rather, of shifting them to the east and south, only served to speed up this phenomenon. This was accompanied by a technological reinforcement of the control over the new bounds, the ultimate goal being to establish absolute separation (ibidem).

No matter what the context, the true aim of the official discourses is to build a representation of the border as watertight, high-tech controlled, and totally capable of separating us from the others, who are consistently given negative connotations (the illegal immigrant, the bandit, the prostitute, etc.). A number of studies, however, suggest a discrepancy between the discourse and what can be observed in reality. This was clearly the situation on the Austrian-Czech border until 2007 (the year the Czech Republic joined Schengen), with Austria's official speeches claiming control over the flow of illegal immigration thanks to the presence of the army and the use of high-tech equipment. An empirical study of the border, however, showed the existence of practices where randomness, chance and context played a crucial role (Darley, 2008). Checks were performed in a more or less thorough fashion depending on the time of day (or night), nationality and gender of the person in question, etc. - in other words, depending on a number of factors that made the border a less watertight place than was claimed by official discourse. These findings led the study's author to the following conclusion: "It seems that simply by virtue of their geographical provenance, local players in border areas are permitted to distance themselves from core representations of the border as a site of rigid, mechanical control" (ibidem). 
In spite of its physical makeover (thanks to the construction of walls and lookout towers) and its being subjected to panoptic surveillance systems, the border remains a dynamic place where certain practices are carried out that are intrinsic to the border's condition as a boundary (between national states, but also between what is legal and illegal, what is legitimate and illegitimate). The example described below shows that the border is a lot more than the official delimitation between two nations: it is an unstable, loosely outlined place, a kind of innermost geography marked by the moving around of human beings and goods.

For a paradigmatic illustration of this kind of situation let us consider the players involved in drug trafficking on the border between Ciudad Juarez (Mexico) and El Paso (United-States) (Guez, 2008), two cities that, seen from the vantage point of, say, Google Earth, form one gigantic conurbation separated by the infamous fence erected between the two countries. The subjects interviewed by Guez are variously involved in the illegal drug trade. They all live at (and off) the border, which the author sees in terms of its interactions with the territories, the people and the projects it links and networks with. Controlling the border is crucial to criminal organizations (as the mere act of crossing it causes the price of the merchandise to inflate instantly), but it has also become a goal for the small drug carriers, who view it as the promise of a different life, a symbol of hope. What this means for the latter is that the border exists even before they lay their eyes on it. In fact, from the moment they decide to carry drugs to the border, those small-time smugglers have already crossed the "borderline" between what is legal and illegal, which the border - with its barbed wire, its law enforcement officers and its legal violence - seems to reify. What truly stands out, in Guez's survey, is the complex, special, almost intimate relationship between the interviewees and the border(s) they have to cross so they can live:

The border line is moving: it is actually more like a fluid continuum between what you do and what you don't, in inextricable connection with the socio-historical moment. Narcotics on their way to the Northern markets bear marks from all the crossings, and in turn the marks of all this trafficking and of the accompanying prohibitions are present in countless places and practices all over the border. (Guez, 2008)

\footnotetext{
${ }^{4}$ Still Guez fails to analyze the economic context and thus explain the growing asymmetry between the two sides of the border. Because of unbridled liberalization in key sectors such as agriculture (a direct consequence of the NAFTA Treaty), Mexico's economic and social organization was severely disrupted, with two million hectares of land lying fallow, eight million peasants forced into emigration to the United States, and also, in 2007 alone, \$1.5 million worth of imported food and thirty peasants emigrating from the country ... every hour! Meanwhile, the United States increased the subsidies to its own farmers (American support to maize producers
} 
This just goes to prove, like many other examples, that we are dealing with a complex phenomenon whose description could be heuristically useful for a metaphorical conception of "the border." On the other hand, it also exposes the border as a source of tension and violence. To put it differently, if, in fact, the border can be conceived of as a place of inventiveness, of resistance to barriers set by domestic state authorities, and as a potential site for alternative economic activities and multiple opportunities, it is because of its inherently dual nature, as both a place of promise and disappointment, of well-being (for the few) and suffering (for the many). It is just not possible to consider the border without taking this fact into account. To put it more accurately, it is not possible to resort to the "border" metaphor without a consideration of the referent's intrinsic ambiguity, just as one cannot draw on its positive aspects alone if one is to contribute toward an overall conception of the border.

Our interpretation of the films in the corpus will find the border concept to be useless unless we bear in mind that, with regard to certain contexts, the concept has no positive connotations whatsoever. Let me illustrate this crucial point with a short sequence from Trance (Villaverde, 2006) in which a German border guard questions a Russian businessman through an interpreter (00:18:38 - 00:20:05). The sequence, clearly influenced by the aesthetics of the documentary, is shot through the dirty window of a border booth. The entire situation, with its suggestion of a sort of glass cage where nothing escapes the observer, is perfectly legible; the viewer inhabiting the fictional space and the traveller in the referential space are equally able to watch the situation unfold.

Neither the border nor the act of translating (incidentally, another notion used in a metaphorical way by the human and social sciences) are to be viewed in a positive light in this case. Here the border is the outer boundary of the European Union, where anything coming from the East is deemed suspicious. In this place you do not translate to reach out toward the other, but because you mistrust him or her. A person's identity matters little in this "in-between" space, and in fact the individual in this scene doesn't even reach character status (for he plays no role at all in the film's overall structure). By staying anonymous, maybe he is a metaphor for what goes on in that particular border on a daily basis. By contrast, the director shows how official borders are no barrier for the mafias who cross 
them at will, as they glide from one country to the next, moving people about as if the latter were merchandise rather than human beings. In another sequence (1:02:40 to 1:05:30) Sonia is sold by her Russian abductor to an Italian pimp. The pimp sizes her up like a colonial trader would a slave. Given the context, translation is not even necessary: "pidgin English" will do perfectly, serving as a metaphor for Sonia's going over from one owner to another (English is no less a necessity than the human "merchandise").

What we see emerging here is the ambiguous and contradictory nature of the notion of border, which partly explains why it has captivated contemporary authors like Ribeiro (2001) and Santos (2000). There is clearly a metaphorical dimension at play, which however points to multiple and often disparate meanings, according to the specific aim of each individual author. Their differences notwithstanding, both Ribeiro and Santos view the border as a symbolic place, a kind of heterotopia - that is, an intracultural shift from the center to the margins, which makes it possible to look at human experience and its representations from a different perspective. Whereas Ribeiro analyzes the border based on literary, essayistic and philosophical representations, Santos views it first and foremost - given its connection with the Baroque and the South - as a place that favors individual emancipation.

In a nutshell, Santos, in his search for ways leading to the consolidation of the emerging paradigm, runs into a substantial problem: the reason the paradigm in question is as yet not in force is not because it is incomplete or filled with tensions (a fact Santos not only acknowledges but actually approves of), but because it is difficult for the incumbent subjectivity not just to grasp, but also, and more importantly, to desire the emergence of a paradigm different from the one it knows or thinks it knows. Hence the need to posit an other, equally emerging - and as yet utopian - subjectivity.

In fact, at such a complex transitional juncture where only the reigning paradigm is well known and the emerging paradigm still awaits to be known and recognized as such, there is a need for a subjectivity that is "able enough to understand and desire the paradigmatic transition," a subjectivity that can turn the fear and anxiety about the future into "emancipatory energy" (Santos, 2000: 321). Such a subjectivity is all the more difficult to generate because it is predicated on a different ethical stance (it must pay constant attention to the consequences of its actions vis-a-vis society and the future) and cannot avail itself of past experiences and discourses nor of those experiences and discourses that have been silenced by official memory. This means that we have to distance ourselves (which in 
turn also means an epistemological shift from the center to the margins) from the canon upon which our modernity was based and solidified into shape (ibidem).

The above contextualization allows us to briefly and easily grasp the role of the border in Santos's thinking on the emerging subjectivity. According to the utopian mold that in some ways characterizes his theoretical trajectory, Santos conceives of the subjectivity in question as based on three topoi and as many metaphors, one of which is the border.

Santos offers a positive description of the border and then proceeds to expand the range of its connotations - in other words, to elaborate on his own metaphor of the border - by drawing on what he sees as a useful paradigm for life on the border: the US western frontier. He explores the heuristic potential of a study on the Western border done by American historians, focusing on some of the features that best fit his own declared goal: "to build the ideal-type of border sociability." He later returns to this particular notion when he writes that what really matters is the "general phenomenology of frontier life," in a context that was marked, before anything else, by the "instability, transience and precariousness of its social life" (ibidem: 325).

However, one of the problems inherent in the metaphorical use - or, to be more exact in the case at hand, in the metaphorical elaboration - of a concept is that one cannot ignore the signifier's immediate meaning(s) or the connotations, both positive and negative, that come with the referent. Ribeiro pointedly notes that the concept is not unproblematic when framed as a utopia, in that the border, as a social construct, can be either a place of hybridization - toward a new identity - or a place of suffering and exclusion. That is one of the problems with any fluid, polysemic concept: while stimulating and open, it is also prone to producing ambiguities and contradictions (Ribeiro, 2001: 471-473).

Although this thinking of/on the border can prove very useful for reading and interpreting the films under consideration, alluding to the frontier land as a place for reflecting on the emerging subjectivity is not without its problems. Both for his vigorous critique of life on the border and for being an intellectual who, like Chomsky, grounds his thinking on a refusal of pure theory, I would like to single out Zygmunt Bauman $(2004,2007)$ from among those authors with the most consistent analyses of the borders created by hegemonic globalization. As we know, at the core of Bauman's thinking lies the notion that, for centuries, the North has been able to dump its "human garbage" onto foreign territories. When the colonies gained their independence one right after another and these territories 
came under the sway of modernity (defined in terms of the establishment of a new sociopolitical order and economic progress), the North had to deal not only with its domestic "garbage" but also with the "garbage" it imported from those former colonies.

Northern cities are teeming with, among others, the unemployed, the new poor, refugees, and second and even third generation immigrant youths. And in order to protect itself, the North gave up "recycling" in favor of building barriers and borders. It now sends the redundant, the "functionless," those whom society cannot put to any economic or political use, to the new ghettos. With the dismantling of the welfare state, the ghettos ceased to function as a protective buffer for the excluded and lost all their positive features simply to be turned into an apparatus of social relegation, i.e., a kind of "dumping ground" for everything that is seen as dangerous and useless. In cities like Paris, certain neighborhoods are now literally beginning to be treated as prisons (difficult to get to by public transportation, blighted by checkpoints and raids), as real prison-houses are evolving in similar fashion: their aim is no longer to re-educate or re-socialize, but just to keep control over that potentially dangerous human waste. Also according to Bauman, there is a clear correlation between, on the one hand, the state's waiving of its social and economic regulatory function, and its promoting of security policies on the other. In fact, this results in the criminalization of many social problems and in the segregation of redundant individuals in more or less confined spaces (such as peripheral neighborhoods, prisons, and closed centers for immigrants).

Taking this context into account, Bauman likens the new borders to what things used to be like on the old frontier. He sees the contemporary social scene as a frontier land similar to that of the Western frontier in nineteenth-century North America, where the absence of laws and regulations worked in favor of the cattle barons and outlaws. Their current counterparts, according to Bauman, are embodied by multinationals and terrorist groups, who are equally responsible for producing "human garbage" - the former in the realm of economic progress, the latter in the domain of "the creative destruction of order." The collateral damage, in terms of human lives, caused by these modern cattle barons and other outlaws are plainly evident in the latter-day frontier. As to the consequences of all these developments, Bauman lists, among others, the fact that life on the border becomes a source of great anxiety, fear (whether the threat is real or imagined, under the circumstances, is less relevant than the reality of fear itself), and instability; that life on the 
border leads to the collapse of mutual trust and its replacement by pervasive mistrust; and that the border generates exclusion for the unwanted and an obsession with security for those living on the inside. Bauman's input, coming from someone whose biography includes a vast, first-hand knowledge of various borders, will perhaps help us qualify Santos's utopian thinking with a touch of the tragic, because for many of the "redundant" or condemned of the earth, borders are, to a large extent and with no cause for celebration, decisive factors in determining the course of their lives.

The fictional illegal migrants in the films covered by the present study are perfect illustrations of Bauman's description of life on the border. Sylvia and Raul, the Mexican migrants in Fast Food Nation; Lorna, the Albanian migrant in Le Silence de Lorna; Sonia, the Russian migrant in Trance; Tarek, the Syrian migrant in The Visitor; Diana, the Estonian migrant of Russian origin in Promised Land; or Bilal, a native of Iraqi Kurdistan in Welcome, are under the constant effects of a life lived on the border. Regardless of their life plans and country of origin, both their status (as illegal migrants) and their place on the border make them into something that is very much like Bauman's human waste. In these films the migrant exists only as a commodity whose use value is measured by his or her labor power, and whose worth lasts only for as long as their bodies can be exploited anyway. Thus, it is no coincidence that almost every film in the corpus includes one sequence where the migrant's worn-out or bruised body is highlighted, because that is when its status as a disposable commodity stands out the most. ${ }^{5}$

From the moment the characters pay the middleman, or, to put it differently, from the moment when, albeit still a long way from the material reification of the border, they set out for it, their past personal histories - what they were prior to the transaction - vanishes from the script. To a certain extent, they lose control over their own trajectory, if for no other reason, because they depend on a trafficker who knows the route to the border. From there on, their autonomy is diminished (Lorna, Sylvia, Carlos, Tarek, Bilal) or nonexistent (Sonia, Diana) and their transformation into a commodity is all but complete.

\footnotetext{
${ }^{5}$ In his biography of the illegal migrant, Nasraoui too gives emphasis to the weakened, sick body, a body without a home: "Physical suffering and disappointment are supposed to be healed at home, which is also where one's potential is restored and balm is poured into the wounds infllicted by life outside. But the migrant worker is exposed to the outdoors: he cannot hide his body, nor his private parts, nor his suffering, and he answers the calls of nature in full view" (Nasraoui, 2013: 208).
} 
The subject's sudden transformation into merchandise is perhaps best depicted by the films that tell the stories of women on their way to illegal prostitution. Thus the opening sequence (0:00:00 to 0:09:35) of Promised Land shows a group of Russian-speaking women being taken by a band of Bedouins toward the Israeli border in the Sinai desert. In spite of its massive militarization, the border proves no obstacle to the Bedouins. The presence of the women on the border is synonymous with their absolute commodification, as they are immediately sold in a kind of modern-day slave auction, conducted in a sort of pidgin English very similar to that of the pimps in Trance. In this long sequence (00:12:48 - 00: 22: 08), the condition of the body parts (breasts, buttocks, mouth) is an indication of the value of the merchandise. There are no names or biographies here, as they are totally irrelevant to the transaction, and besides, the bodies' anonymity reinforces their status as commodity. The vocabulary used by the various parties involved in this trafficking (Bedouins, Palestinians, Israelis of different geographical regions) is itself suggestive of this metamorphosis; cargo, lot, goods are the words they use to literally - i.e., non-figuratively - describe what, from their point of view, the women truly are.

Gitai's film exposes porous physical borders, including those that are virtually insurmountable for the Palestinian population. Thus, the traffickers lead a group of women to Ramallah without a problem, the Israeli army checkpoint proving no obstacle for them. The officially hermetic border, supposedly a barrier for ensuring the safety of the Israeli state and its citizens, is portrayed as being permeable and ineffective, a place of contraband and exploitation. In this regard, Promised Land is an accurate portrayal of the gap between official discourse on the border and the border as a dynamic, criminogenic phenomenon. For all practical purposes, geography - Mexico-United States, Israel-Palestine, India-Bangladesh - matters little or nothing, because an unbalanced power relationship between the two sides, or a situation of asymmetrical economic development between two countries, is all it takes for the border to become a site of corruption, violence and alienation, ${ }^{6}$ with economic and social emancipation being mostly linked to the traffickers and border guards.

For the fictional illegal migrants, however, crossing the physical border does not mean the end of their situation as border beings. In Fast Food Nation, the Mexican group that comes

\footnotetext{
${ }^{6}$ A fact emphasized by Sassen in her reflections on the connection between migrations and neoliberal globalization: "As a matter of fact, as the countries of destination have repressed illegal entry and semimilitarized ever larger sections of their borders, there has been a sharp increase in illegal human trafficking" (Sassen, 2002: 41).
} 
into the United States to find work in a meat packing plant do not lose their commoditybody status. Linklater's film establishes an intimate connection between the migrant as essentially a border being and the workings of the neoliberal economy, which to a great extent is dependent on the border to maintain its profits. The film weaves together the paths of a group of Mexican migrants and the investigation conducted by Don Anderson, a top manager of the multinational company the former also work for. The editing suggests the illegal migrant's central role in the meat processing industry: the initial sequence is constructed as an ad for the multinational in question, but a slow zoom to a piece of grilled meat makes the viewer understand that the film is somehow going to "dissect" the process whereby the meat finally reaches the consumer. Another sequence follows (exterior, Mexican-American border, night) showing the group of migrants about to embark on their journey. The alternate editing thus links the world of the illegal aliens with that of the meat packing plant, and the very use of this type of editing helps the viewer understand Linklater's intent: to show that in some sectors of the neoliberal economy those two worlds are inextricable.

It is no coincidence that, in the course of his inspection visit to the meat plant where the migrants work (00:26:13 - 00:28:30), Anderson, who has been given the task of finding out the reason for the presence of fecal matter in beef, is only interested in the material conditions of production (hygiene, cleaning of equipment, etc.), taking no notice of the status of the migrant workers in the production line. He literally misses them and their constant exploitation. The sequence ends with the group attending a session on the prevention of occupational accidents. Don walks right by the group without stopping, as if they were a natural element of the setting.

The presence of this character, Anderson, a mature man going through a sort of crisis because of what he is able to dig up in relation to industrial meat production, permits me to focus on another feature of the border that also gets to be depicted in the films in the corpus: the inclusion of a Western citizen who meets the illegal migrant while experiencing a personal crisis.

\section{The Indispensable Border Intermediary: The Middle-Aged Western Man-in-Crisis}

In a number of films selected, the illegal migrant shares the script with another character the middle-aged, Western man in the midst of a personal crisis (as a result of a divorce or 
the death of his wife), who finds some comfort in the company of the illegal migrant. Simon, the character in Welcome, and Walter in The Visitor, will at some point find themselves face to face with the Other, an undocumented border being waiting to cross over to the side where they call you a citizen. Thus, until he meets Tarek and Zainab, the couple he finds living in his New York apartment, Walter is shown almost exclusively in interior sequences at home, in his office, in his car - and invariably filmed in medium long shot or medium close-up. Shot scale is highly significant in this case, as it allows for the face of the main character to be analyzed, while also reinforcing a certain sense of confinement. It would not be off the mark to see this type of framing as a metaphor for Walter's lifestyle.

A line clearly bisects - or rather, gives structure to - The Visitor, thus establishing a dichotomy between an inner and an outer space (connoting boredom and life, respectively), when Walter comes across young musicians using plastic buckets as drums in a New York City park. It is outside the university walls that Walter feels the pulsating rhythm of life. A colleague walks by and invites him back inside. The fact is, however, that from now on, the in-side (meaning both Walt's inner life and his home) will never be the same. The change is illustrated in the sequence showing his first djembe lesson with Tarek (00:22:57 - 00:26:26). Whereas early in the story we see Walter playing the piano by himself in the gloom at home, now a similar shot scale shows him smiling under a bright light. Here the long shot no longer serves to highlight Walter's loneliness, but becomes necessary, in filmic terms, both to show how light fills up the scene and to make room for Tarek. There is another telling sequence in this connection: after the concert in the park, Tarek and Walter walk together in a medium long shot; little by little a zoom movement increases the shot scale to an extreme long shot encompassing the park, the people, the city and, finally, the radiant light. Walter's happiness seems to expand with the zoom-out.

It is important to note, albeit briefly, that this Other who represents salvation for the character going through a crisis also makes her/his appearance in movies where the migrants and their children are legal residents of the host country. This is the case in Gran Torino (Eastwood, 2008), a film in which the character of Walt Kowalski, played by an ageing Clint Eastwood, succeeds in redirecting his own life and investing his death with meaning by connecting with his Hmong neighbors in general and young Thao in particular (with Thao serving as the counterpart, on this side of the border, of Tarek and Bilal, who come from the other side). Clintwood's film shows an endless series of borders, some of them visible, 
others less so, some public, others private in nature, as well as numerous instances of borders being violated.

A sort of invisible line could be said to separate Walt from his neighbors, so that the boundaries of his property establish a cultural border that stays impregnable for part of the film. From Kowalski's point of view, on this side of the border is "civilization" (the English language, the American flag, his tidy lawn, his well-kept house), while on the other are what he sees as "the barbarians" (a different language, an unmowed lawn, a house in rather poor condition). The other side is unknown to him, and in his worldview the Hmong are no different from the Koreans, Chinese, or Asians in general. Let it be noted in passing that on the other side, acting as Walt's counterpart, there is the grandmother, who at first is also reluctant to have a white, American neighbor (see the sequence in which she addresses him in Hmong, asking why he is still living in the neighborhood). The viewer understands that Kowalski undergoes a transformation as soon as characters start crossing this border, thus generating fluidity and movement from one place to another - in other words, when, first, Walt acquiesces to cross over to share a Hmong meal, and then when he accepts Thao into his private space as a helper.

These multiple border crossings draw attention to the fact that it is possible to move from one side to the other, despite the dominant representations on either side. Such mobility unveils a world that is going through great changes. It is American society as a whole - not unlike any other Western society - that is faced with the arrival of new immigrants (accompanied by mutual mistrust and sometimes fear as well). One short sequence in particular, when Walt goes to the hospital for tests, perfectly illustrates this situation: Observing the other patients while sitting in the waiting room, he notes that many are foreign-born, as is the nurse and the new female doctor. Walt's world is changing rapidly, perhaps at a faster pace than at any other time in the history of his world.

If there is a single character in these films that may be said to draw a positive experience from what happens in this border context, that would be the recurring figure of the Western man going through an existential crisis. By coming into contact with the Other, Walter, Simon and Walt move away from the root of their unhappiness and embark, as it were, on an inner journey that causes them to redefine their own identity. The border then becomes a site of hybridization and also of salvation for the citizen (of the North) without a purpose, but not for the subject (of the South) in search of a safe haven. 
Let us keep in mind that hybridization as an extreme experience inherent to life on the border is largely celebrated in the writings of Ribeiro as well as Santos. According to Ribeiro, if it weren't for borders it would be difficult to conceive of hybrid or mongrel identities, because the border is the foundation of the elements - plurisignification, ambiguity, heterogeneity - underlying this type of subjectivity. Ribeiro's analysis of the border phenomenon takes into consideration the tensions and the uneven power relations that characterize hybrid identities. In his view, the border is not clearly defined, hence his rejection of "the notion that the border 'line' establishes a rigid, binary demarcation between an inside and an outside, between that which is wholly familiar and that which is totally alien, with no room left for mediation or integration" (Ribeiro, 2001: 471). What the author suggests in relation to border sociability evokes the life experiences we encounter in certain fictional characters: "The border is a medium of communication, the living space where the self and the other come to find the possibility of sharing, which is to say the possibility of generating new identity configurations" (Ribeiro, 2001: 471).

The reason the directors of these three films opted for an aesthetics of illusion, total legibility, and an intermediary the viewer can identify with, is largely because they want to persuade/seduce Western audiences (and as it happens, Gran Torino, The Visitor and Welcome all did very well at the box office). Other films, such as Le Silence de Lorna, Promised Land, Trance or Lilya 4-Ever, are marked by an aesthetics of allusion, reliance on metaphor to convey the evolution of the migrant characters, and the absence of an intermediary. Besides, they all raise the issue of the viewer's gaze on the border: how does one see the illegal migrant and, a fortiori, how does one regard the body of the woman that is trafficked across the border (as is the case in the last three films)?

\section{The Relevance of the Viewer's Point of View}

The question of the receivers' role and their relationship with the diegesis has long been a theoretical concern of film analysts: who "receives" films and in what manner? As recent film analyses show (see Garraio, 2011), there is no avoiding the issue of the position of the receiver in the fictions we are dealing with here, namely the gaze of the receiver in relation to the body of the trafficked woman. The viewer's gaze and point of view thus seem indispensable to the representation of the illegal migrant on the border, since every film, regardless of its aesthetic choices, tends to implicate the receiver. 
The films' aesthetics hinge, to some extent, on the following preliminary question: what to do with the bodies that are violated on the border? Should they be represented on screen or off screen? The answer to these questions led Gitai, Villaverde and Moodysson to make certain aesthetic choices rather than others. In Promised Land, the Israeli director chose to shoot with digital cameras to enhance the reality effect. In addition, the inherent technical characteristics of these (small, lightweight) cameras allowed him to follow the characters closely, as if walking alongside them. ${ }^{7}$ The sequence showing the auctioning of the women in the desert is a paradigmatic illustration of the relationship between technical choice, aesthetics and meaning: the camera moves among the bodies, eyeing them up as if it were a trafficker. As a result, thanks to the subjective camera the viewers at this point find themselves looking at the bodies as if they were just another trafficker. Hence, no doubt, the uneasy feeling they are left with. Later, when the women are taken through the checkpoint by the traffickers, several anonymous bystanders stare directly at the camera lens. Here the director chose not to hide the camera, thus transgressing the boundaries between fiction and documentary (a genre whose codes include the use of the gazing camera and the camera's assumed presence), which in turn makes the viewer feel that $s /$ he her/himself is being observed. It is at this exact point, where the receiver's status changes from observer to observed, that lies, perhaps, the interconnection between aesthetics, point of view and ethics, since by doing it Gitai leads the viewer to question, not forced prostitution (which is outrightly condemned), but the values and the morals of the socio-economic system on which, to a greater or lesser extent, it is founded.

Although resorting to different devices, both Lilya 4-Ever and Trance also place the whole issue of the viewer's gaze at the center of their respective concerns. The former film places the viewers in an uncomfortable situation when it makes use of the subjective camera to put them face to face with the sexual violence perpetrated against the main characters: a sequence consisting of a rapid succession of shots shows the faces of the clients on top of the victim, which in this instance means that the gaze of the viewer and that of the victim

\footnotetext{
${ }^{7}$ Here's what Gitai had to say on the subject: "I [...] wanted to move through the various arenas of the story more fluently and really try to capture the nuances of the relationships between everyone involved. This needed a much more 'live' camera strategy. Small digital cameras allowed us to get in very close and project a sense of intimacy into the film. This roughness can give a sense of urgency. I found it fascinating that the camera was always ready with the capacity to register a kind of exposed nerve." (Quoted in Garraio, 2011).
} 
blend together. Once again, aesthetic choice carries clear ethical implications. ${ }^{8}$ In Trance, in some ways the most complex and perhaps the least accessible of all the movies in the corpus, Portuguese director Teresa Villaverde constantly challenges the gaze of the viewer, which at times she brings onto the scene. Thus, a sequence that comes after Sonia is raped by her Russian abductor offers a static shot of her getting dressed in the background, as the rapist's back is shown foreground left in medium close-up, gazing at her naked body (0:55:09). As this configuration of filmic space first unfolds, the viewer's gaze duplicates that of the rapist, which in itself renders the former's position rather uncomfortable to begin with. But when the rapist lies down and stops gazing, the viewer' situation becomes next to unbearable, because at that exact moment there is no longer an intermediary between that body and the "I-spectator" that sees it. Villaverde radically forces viewers into a sort of double bind: to refuse to be a voyeur, which would eventually make them stop watching the film; to incessantly question their own point of view about the suffering body. In either case, the viewers find themselves in a complex, disturbing position, halfway between complicity and critical distance.

Finally, in Fast Food Nation only the viewers have access to all the information, as they follow both Don's investigation and the migrant group's quest for a better life. For example, only the viewers get to know what happens to the anonymous migrant who strayed from the group while in the desert only to die there. From their privileged position, the viewers alone are given to understand that, although Anderson and the Mexicans may never communicate, their paths are closely linked. See, for instance, the short sequence in which Don's car and the van where the migrants are hiding stop side by side at an intersection $(0: 15: 37)$, a symbol of both encounter and separation. At this juncture the viewer understands that, although they never come into actual contact in the diegesis, the characters are inextricable within the economic and social system portrayed.

\section{Conclusion}

Why did these directors choose to focus almost exclusively on a given type of migrant - the "illegal" migrant - to the detriment of others? Perhaps because, on the one hand, illegal migrants carry all the suffering inherent to life on the border, and on the other, because they

\footnotetext{
${ }^{8}$ It is worth mentioning that Lilya 4-Ever has been used by NGOs to raise awareness among certain target populations on the issue of trafficking in women for sexual exploitation (Garraio, 2011).
} 
are the ultimate symbol of the negative consequences of the asymmetries generated by the neoliberal organization of the economy. As we have seen, these films depict the illegal migrants either as they get ready to cross the divide that physically separates the South from the North, or when they are already on the other side of the border, looking for a different kind of life. Regardless of where the character happens to be, $s /$ he is subjected to the experience of the border and its - mostly negative - effects. We now know that this type of sociability emerges well before the subject's arrival on the geographical border between any two given countries. Let it be said, in this regard, that these fictional narratives tend to locate the geographical starting point of this kind of border experience in places controlled by Western (be they European or North-American) police forces, namely retention centers for "illegal" migrants. The fact is, however, that, as far as the illegal migrant is concerned, the negative effects of the border sociability often begin to be felt well before arrival at the camp. In fact, with control of the EU's external frontiers being delegated to some Maghreb countries (European Council in Seville, June 2002), it is becoming increasingly common for this painful sociability to be experienced in retention centers based in the South, particularly in Morocco (Boukhari, 2007).

Finally, let me just mention how the human and social sciences complement one another in this type of analysis. In the case at hand, no internal film analysis was offered, nor were the films read as documents. Instead, it was variously pointed out that, if a film is rooted in the social, it does so thanks to the use of rhetorical devices, characters, and narrative configurations that articulate the social in a particular way. Such particularity is perhaps best revealed at another border, the one that runs across the sciences. ${ }^{9}$

Translated by João Paulo Moreira Revised by Teresa Tavares

\section{References}

Bauman, Zygmunt (2004), Wasted Lives. Modernity and its Outcasts. Cambridge \& Malden: Polity Press.

Bauman, Zygmunt (2007), Liquid Times. Living in an Age of Uncertainty. Cambridge \& Malden: Polity Press.

\footnotetext{
${ }^{9}$ The integration of various sciences also serves to demonstrate the critical importance of the humanities for understanding this world of ours (on this point, see the entry on the humanities by António Sousa Ribeiro in the Dicionário das Crises e das Alternativas, 2012).
} 
Bennafla, Karine; Peraldi, Michel (2008), "Frontières et logiques de passage: l'ordinaire des transgressions," Cultures \& Conflits, 72. Accessed on 21.06.2009, at www.conflits.org/index17383.html. DOI: 10.4000/conflits.17383

Boukhari, Sophie (2007), "La longue traque des migrants clandestins au Maroc," Le Monde diplomatique, May, no. 638, pp.16-17.

Darley, Mathilde (2008), "Le contrôle migratoire aux frontières Schengen: pratiques et représentations des polices sur la ligne tchéco-autrichienne," Cultures \& Conflits, 71. Accessed on 22.06.2009, at www.conflits.org/index16583.html. DOI: 10.4000/conflits.16583

Fassin, Eric (2009), "L'immigration, un 'problème' si commode", Le Monde diplomatique, November, no. 668 , p. 22.

Garraio, Júlia (2011), "Prostituição forçada de migrantes de Leste no cinema europeu contemporâneo," e-cadernos CES, 14: 77-102. Accessed on 03.11.2014, at http://eces.revues.org/897. DOI: 10.4000/eces.897

Guez, Sabine (2008), "La frontière et au-delà. Une enquête ethnographique sur le narcotrafic à Ciudad Juarez (Mexique) et El Paso (États-Unis)," Cultures \& Conflits, 72. Accessed on 21.06.2009, at www.conflits.org/index17363.html.

Makaremi, Chowra (2008), "Pénalisation de la circulation et reconfigurations de la frontière: le maintien des étrangers en zone d'attente," Cultures \& Conflits, 71. Accessed on 22.06.2009, at www.conflits.org/index16133.html. DOI: 10.4000/conflits.16133

Mandelbaum, Jacques; Ridet, Philippe (2011), "L'immigré, vedette américaine de la Mostra de Venise," Le Monde, 11-12 September, p. 18.

Mandelbaum, Jacques; Sotinel, Thomas (2009), "La figure de l'immigrant clandestin au cinéma," Le Monde, 28 March. Accessed on 20.11.2011, at http://www.lemonde.fr.

Nasraoui, Mustapha (2013), Le migrant clandestin. Le paradoxe de l'être et de la société. Paris: L'Harmattan.

Ribeiro, António Sousa (2001), "A retórica dos limites. Notas sobre o conceito de fronteira," in Boaventura de Sousa Santos (ed.), Globalização. Fatalidade ou utopia? Porto: Afrontamento, 463488.

Rush, Elisabeth (2012), "Inde-Bangladesh, la frontière déjouée," Le Monde diplomatique, August, no. 701, pp.6-7.

Santos, Boaventura de Sousa (2000), A crítica da razão indolente. Contra o desperdício da experiência. Porto: Afrontamento.

Sassen, Saskia (2002), "Is this the way to go? Handling immigration in a global era," Eurozine, 22 July. Available at http://www.eurozine.com/pdf/2002-09-17-sassen-en.pdf.

Sotinel, Thomas (2009), "Le maître-nageur dans le grand bain des migrants," Le Monde, 11 March. Accessed on 11.09.2011, at http://www.lemonde.fr.

UNDP (2009), Human Develelopment Report. Overcoming barriers: Human mobility and development. New York: United Nations Human Development Programme.

Vigna, Anne (2008), "Le jour où le Mexique fut privé de tortillas," Le Monde diplomatique, March, no. 648 , pp. 8-9.

Vigna, Anne (2009), "A Tijuana, la mauvaise fortune des maquiladoras," Le Monde diplomatique, November, no. 668, pp. 18-19. 